\title{
The Effects of Business Intelligence on the Effectiveness of the Organization (Case Study: Airline Companies in Iran)
}

\author{
Mahsa Rayat ${ }^{1}$ \& Hamid Reza Rezaei Kelidbari ${ }^{2}$ \\ ${ }^{1}$ Human Resource Management, the international unit of Bandar-e Anzali, Islamic Azad University, Bandar \\ Anzali, Iran \\ ${ }^{2}$ Department of Public Administration, Rasht Branch, Islamic Azad University, Rasht, Iran \\ Correspondence: Hamid Reza Rezaei Kelidbari, Department of Public Administration, Rasht Branch, Islamic \\ Azad University, Rasht, Iran. E-mail: hrezaee41@yahoo.com
}

Received: June 7, 2017

Accepted: June 13, 2017

Online Published: August 23, 2017

doi:10.5539/res.v9n3p176

URL: http://doi.org/10.5539/res.v9n3p176

\begin{abstract}
Given the increasing competition between airlines companies in the country and equipping them with modern information technologies, establishment of knowledge management system in airline industry can increase the effectiveness of business intelligence system and lead to effectiveness of this industry. The aim of this study was to identify the effects of strategy, structure, processes and organizational culture on the effectiveness of organization and mediating role of business intelligence systems in Iran's airline companies. Statistical society includes all airlines of Iran. For sampling, non-random judgmental sampling method is used. In order to study the research hypotheses, structural equation methods have been used. Questionnaire tools were used for gathering the data. Stability of the questionnaires used in the present study was calculated higher than 0.7 in term of Cronbach alpha, confirming the validity. The results showed that there is a positive and significant effect between variables of strategy, structure, and organizational culture on the effectiveness of the organization and business intelligence systems in Iran's airlines and that there is not a significant relationship between organizational variables and organizational effectiveness.
\end{abstract}

Keywords: organizational culture, organizational strategy, organizational structure, organizational effectiveness

\section{Introduction}

Today in the changing business environment, business intelligence systems play important role in supporting the decision-making and improvingthe organizational performance. These systems help the companies in storage, retrieval, and analysis of large volumes of data and information on company operations and allow the companies to improve their strategic and apathetical decisions so that they can attain at the competitive benefits defined in BI as "the process of collecting, modifying and distributing the information purposefully which reduces uncertainty in all strategic decision-makings and in every strategic decision". These systems are composed of a set of concepts, processes and methods to improve business decision-making, where the data derived from various sources (for example, internal and external sources such as customers, partners and third-party) is used to understand the dynamics of business (Shamsolarefin et al., 2015). In general, business intelligence is a set of concepts, methods and processes which not only improve the business decisions, but also support the organization's strategies. Business intelligence systems help users recognize and solve the problems, detect the business risks and opportunities, predict the market processes, estimate the activity of competitors, better understand the business requirements and better manage the clients and relationships among suppliers. Using such systems, managers can more quickly response the problems and estimate correctly the condition against the competitors, leading to gaining the competitive advantage by the firm (Lajevardi \& Rahimi pour, 2012, p. 10).

In addition to the direct impact on the effectiveness of an organization's business intelligence system, four variables including organizational culture, organizational strategy, organizational structure and organizational processes which are considered as organizational factors can influence the effectiveness of the organization. Business intelligence systems, as intermediates, can promote the effectiveness of the organization and organizational factors, increasing the organizational effectiveness in the organization. With regarding to the competitive environment of aerial industry in the world, regional conditions of Iran despite of highly efficient airlines in the Persian Gulf area and west of the country and also development plans of the airlines in middle 
Asian countries, it is inevitable to equip Iranian airlines with modern information technologies. To deploy the knowledge management system in the airline industry for more effectiveness, intelligence systems can be one of the most important alternatives. This study aims at examining the impact of strategy, structure, processes and organizational culture on organizational effectiveness through business intelligence systems in airline companies of Iran. Therefore, the main question is whether the strategy, structure, processes and organizational culture have an impact on organizational effectiveness through business intelligence systems in Iranian airlines.

\section{Literature}

Nazari et al. (2015) in a study recognized and gained knowledge about communication skills, leadership styles, organizational culture and organizational effectiveness of sport managers and explained the relationships between them. Based on the obtained results, there is a significant relationship between communication skills, organizational culture, leadership style and organizational effectiveness among sport directors. Vaezi and Forouzanfar (2013) reviewed the mediating role of knowledge management in the relationship between organizational factors (structure, culture and strategy) and organizational effectiveness in Saipa Company by using structural equation modeling. The results showed that there is a significant relationship between the structure and organizational culture and knowledge management. Also, there is a significant relationship between organizational factors and effectiveness of organization and between knowledge management and organizational effectiveness. Haghighat Monfared and Shaban Mayani (2012) studied the effect of content dimensions of organization (culture, technology, strategy) on effectiveness of business intelligence with regarding to the moderating role of knowledge management in Saman bank. Results of the research indicate a positive and significant relationship between content dimensions of organization and effectiveness of business intelligence and also indicates that knowledge management as a mediating variable enhances the relationship between content dimensions and effectiveness of business intelligence.

Lajevardi and Rahimpoor (2012) in a study examined the business intelligence and its impact on improvement of performance management in Ports and Maritime Ports Department of Gilan. First, the impressive dimensions of business intelligence and effective indices were determined for each domain which had been evaluated in the form of 4 technical dimensions, organizational, business and operational dimensions and 44 indices.

Next, by using the analyses, the information collected from questionnaire was ranked so that the most effective dimensions and indices were determined. The results indicated the effectiveness of indices from the view of IT experts and port affairs. Reporting analyses of BI which were combined with key performance indices and dashboards helped port and maritime executives achieve continuous improvement, quality and timely access to reports and strategic decisions. Ardalan et al. (2012) in a research examined knowledge leadership, organizational intelligence and organizational effectiveness. The purpose of identification was to review the relationship between knowledge management and organizational intelligence and organizational effectiveness in Bu-Ali Sina University of Hamedan. Results showed that condition of knowledge leadership, organizational intelligence and organizational effectiveness is above the average. Pearson correlation coefficient made it clear that there is a significant and positive relationship between knowledge leadership and organizational intelligence and organizational effectiveness. Results of multiple regression analysis indicated that among criteria of knowledge leadership, criteria of supporting individual and group learning process have maximum impact on predicting the organizational effectiveness.

Among organizational intelligence criteria, criteria of unity, agreement, strategic insight and common fate have maximum impact on predicting organizational effectiveness, respectively. Rahimi et al. (2012) in a study examined the relationship between multiple intelligences of CEOs with organizational effectiveness of Gas Company of Azarbayjan-sharghi. The results indicate that multiple intelligence of CEOs is associated with organizational effectiveness of Gas Company of Azarbayjan-sharghi.

Larson and Chang (2016) in a study examined business intelligence, agile methods, data science and the development of life cycle of business intelligence. The results indicated that phenomenon of data magnitude, size, variety and speed of data have an impact on BI and using the obtained information. Fink et al. (2016) in a study examined the relationship between business intelligence and organizational learning and reviewed the value creation processes in an empirical research. Their model was designed to investigate these relationships and tested them in three companies. The results showed a significant relationship between business intelligence and organizational learning. Banerjee and Mishra (2015) in a survey reviewed the solutions for retail supply chain management in India based on business intelligence view. In their study, the views of managers of a major food retailer in India about the practices of supply chain management, competitive advantage and firm performance were studied. Findings indicated that there is a significant relationship Business Intelligence (BI) and customer 
relationship management aspects. Shamsul Arefin and colleagues (2015) in a study identified the effects of strategy, structure, processes and organizational culture on organizational effectiveness and possible mediating role of business intelligence systems (BI) among them. The study included 255 organizational units in Bangladesh where they were analyzed and by means of partial least squares method, and statistical analysis technique based on structural quotations modeling. The results showed that organizational factors, such as strategy, structure, processes and culture of the organization effectiveness have a positive effect on BI system's effectiveness and effectiveness of organization. In addition, effectiveness of BI systems was somewhat an intermediate between the effects of the strategy, structure, process and organizational culture on organizational effectiveness. Weinberg et al. (2013) in a study reviewed the social business destination through studying a journey of an organization with social media and community cooperation. In this article the main features of the evolution of the organization as a social business network in response to a social market were drawn.

\section{Theoretical Principles of Investigation}

The aim of this study was to investigate the effects of business intelligence on the effectiveness of the organization in Iran airlines. Then, first the concepts related to organizational effectiveness and business intelligence and also organizational factors will be examined.

\subsection{Effectiveness}

Effectiveness was defined as the degree or extent to which an organization realizes its goals. Peter Drucker, the great management thinkers, defines effectiveness as "doing right things". Richard Daft considers the understanding of organization's purpose as one of the first step in understanding the effectiveness of the organization. He defines the objective as desirable condition of an organization in the future and states that the effectiveness is the degree or extent where organizations achieve their goals. He believes that effectiveness has a general concept and contains a large number of variables (Daft, 1998, p. 64).

Organizational effectiveness is defined as the extent in which an organization attains at its aims by using certain resources and without wasting its resources and unnecessary aging of members and society. In fact, Organizational effectiveness (OF) shows that how close is an organization to its goals. In the other words, it is the extent to which an organization realizes its goals (Javaheri Kamel, 2014). In fact, effectiveness means studying the effectiveness of the measures taken in order to achieve the predetermined goals. In simple terms, in a study on effectiveness, extent of goal attainment is measured. However, it seems that we should make a further step toward defining effectiveness, meaning that effectiveness is obtained in an educational course when: 1) Educational requirements are clearly recognized, 2) Proper plan is designed for meeting the needs, 3) Designed plan is correctly implemented, and 4) Education process and objective attainment are properly evaluated (Eslamie, 2007).

\subsection{Business Intelligence}

Business Intelligence (BI) is a technology-based process applied for analyzing the data in order to help senior managers, middle managers and other users to make the optimal decision. Business Intelligence includes a series of tools, applications and methodologies which prepare the data for analysis by collecting data from intra- and extra-organizational sources. It also allows the surveys and creates the reports and dashboards so that these reports are made available for decision-makers and the staff. Intelligence plays an important role in the social structure. Recent researches of psychology studied the individual intelligence, looked for the nature of intelligence and tried to define it. Intelligence is the ability to learn, reason and comprehend. Moreover, intelligence is defined as the ability of a person to evaluate and control his knowledge about the surrounding data, reconstruction of new knowledge and transformation of data into the experience and goal attainment. Improving OI is necessary for increasing the capacity of innovation. In addition, management activities and performances must focus on OI in order to survive the organization. OI refers to management of intelligence measures in various commercial and governmental sectors. Although there is a lack of comprehensive studies on organizational intelligence, psychological research on intelligence has formed the principles and basis of organizational intelligence. Organizational intelligence was first proposed by Matsuda in 1992 in an article titled "Organizational Intelligence, its importance as a process and product". Matsuda regards organizational intelligence as a combination of two factors: human intelligence and machine intelligence and dividesit into five components: the organizational knowledge, organizational memory, organizational learning, organizational communication and organizational reflection (Ardalan et al., 2012, p. 75).

The main goal of Business Intelligence Systems is to provide knowledge workers with the tools and methods that help them make effective and timely decisions. If decision-makers trust in using such tools, we can expect that general quality of decision-making significantly improves. With the help of mathematical models and algorithms, 
analyzing a large number of operations is possible and we can achieve effective and timely decisions and achieve our favorite result. Therefore, the major benefit of using business intelligence systems is to increase the effectiveness of the decision-making process. Large amounts of data exist in information systems of organizations. Part of the transaction data is from internal and some other part is from external sources. Even if these data are collected and saved systematically we can not use them for decision-making directly. The data must be extracted by appropriate means and by using methods of analysis, they should be processed and converted to information and knowledge so that they can be used in the decision making process (Shamsul Arefin et al., 2015). Via the following components, business intelligence converts the data to information and leads it toward knowledge (Gul et al., 2014).

\subsubsection{Data of Warehouse}

A data warehouse is a set of integrated data, which is collected by the web pages of internal and external sources and it aggregates associated data from a storage which is available for decision-making. Data warehouse is very accessible, especially for managers and business analysts.

\subsubsection{Data Mining}

Data mining is the process of discovering patterns, relationships between data and trends by analyzing large volumes of information that is stored in the warehouse. Detection technology, statistical and mathematical techniques are commonly used in data mining technology.

\subsubsection{ETL}

Summingup, transferring and loading a series of operations in which data is extracted from multiple databases and systems and it is transferred to the format and next it is loaded in the target database.

\subsubsection{OLAP}

OLAP technology uses complex calculations that enables users to search and analyze large volumes of information. OLAP tools are a combination of graphical user interface and processing methods, which creates different visual results in view of its users.

\subsection{Organizational Factors}

Resource-based view was reviewed for recognizing the relationship between organizational resources and its impact on value creation. A resource-based view describes rare, precious, and unique organizational resources and produces sustainable competitive advantages for the companies. Organizational resource covers a wide range of valuable assets controlled by the organization, including management skills, organizational strategy, culture, processes, structure and firm characteristics, which enables companies to increase their performance and to guarantee it. The researchers argue that resources applications with resource-based view acquire long-term success of company by measuring the strategic value of IT resources. In addition, the fit between organizational resources relies on the best possible organizational design which is subject to numerous internal and external factors. According to contingency theory, previous studies argued the importance of fit among subsystems and factors such as technology, people, information, strategy, culture, processes and structures that finally ensure the long-term performance of the company. In other words, organizational factors are regarded as non-IT resources, enterprise subsystems, and complementary of IT resources. In line with the vision and resources based on contingency theories, it is stated that organizational factors, such as organizational strategy, structure, culture, and processes, have an impact on the effectiveness of IT systems that infinitely affect organizational effectiveness (Shamsul Arefin et al., 2015).

\subsubsection{Organizational Strategy}

Strategy is defined as routes with different alternatives for reaching goals and strategic organizational objectives. It suggests ways to achieve organizational goals that show how we can achieve a better situation. In fact, strategy is a planning for optimum usage of organizational facilities including recognition and organizing organization's ability in order to survive and to become compatible with environmental condition (Haghighat, Monfared, \& Shaban Mayani, 2012, p. 68). The relationship between organizational strategy and effectiveness of business intelligence systems is obvious. One of the major objectives of applications in business intelligence systems is providing useful and timely information, so senior management can make valuable decisions in line with steering organization toward success. Main alignment between business strategy and IT strategy for organizational performance is desirable. While firms with high-performance guarantee IT strategic alignment and the researchers showed that companies with low performance are more likely to face contradictory situations and poor alignment between strategy, business structure, strategy and IT structure. Some researchers argue that 
strategic IT alignment depends on such factors as industry, environment ambiguity, knowledge sharing culture and previous information system success. A growing plan of researches described the mediating role inconcentrated organizational strategy which focuses on IT capabilities and organizational effectiveness (Shamsul Arefin et al., 2015).

\subsubsection{Organizational Structure}

The organizational structure explains how duties are allocated, to whom staff is reported, and what are official coordination mechanisms as well as which organizational interaction patterns must be followed. We define structure as a component of the organization's structure, the element of complexity, formality and concentration. Organizations are regarded as "consciously coordinated" term which is coordinated with awareness and it has a relatively certain domains. It acts towards reaching goal or goals based on constant basis hierarchy. The term "coordinated with awareness" implies management. "Social phenomenon", indicates that organizations are formed of people or groups of individuals who interact with each other. An organization has relatively clear boundaries. The borders can change over time, and may not be completely clear. However, there should be certain limits to be able to recognize members of the organization from non-members. Finally, organizations were established to perform affairs. This state of affairs or activities are the ends, which can not be achieved by a single individual. If they are achieved by an individual, they are more effective than they are achieved by an organization. The organizational structure defines how the duties are allocated, who reports to who and which official coordination mechanisms as well as the organizational interaction patterns must be followed? We define component as one of the organization's structure, which is formed of the element of complexity, formality and concentration. Complexity shows the extent of separation within the organization. It also points out the level of skill orientation, division of labor and the number of levels in the hierarchy of the organization. It defines limits where organizational units are geographically dispersed. Of course, complexity is a relative term. The extent to which an organization relies on rules and regulations for directing the behavior of employees is called recognition. Focus suggests to the point to which decision-making authority refers. In some organizations decision-making is heavily centralized. Usually it shows centralization and decentralization on a continuum (Yarahmadi, 2012).

\subsubsection{Organizational Processes}

Process is a set of interdependent activities which converts inputs to outputs in each step by consuming one or several sources of inputs. The outputs are presented as inputs of other processes so that finally they achieve a certain objective. A system must collect the necessary data and information to measure the process performance. Next, information is analyzed and corrective action or preventive action must be done to improve. The effectiveness and efficiency of the process can be assessed in internal or external reviews of processes (Kharazian, 2014).

Organizational processes (management processes) need information technology, marketing, manufacturing and supply chain management process. The researches showed that complementary nature of marketing and information technology, manufacturing and supply chain management process has a positive effect on firm performance. In addition, the mutually complementary capabilities and enterprise information systems can enhance organizational effectiveness and influence the company's operating performance. Similarly, when the organizational process (process of management) is aligned with the IT infrastructure, an organization may decompose IT-based capabilities or qualifications, leading to improvement of process performance and performance of company. Moreover, the alignment of IT processes has created strong capabilities that have sustainable competitive advantages for the company. When the information system is associated with organizational processes and works with them, a synergistic effect increases the organizational capabilities. For example, processes and knowledge management processes in alignment with organizational capabilities produce organizational capabilities which determine organizational effectiveness (Shamsul Arefin et al., 2015).

\subsubsection{Corporate Culture}

Organizational culture is a system of common inferences of the members about an organization and this feature separates two organizations from each other (Robins, 1995, p. 967). It can be set of basic assumptions, values and common beliefs and apparent signals (Abzari, 2006, p. 52). In an organization, culture plays different roles. First, culture determines organizational boundaries and separates the organization. Second, it gives a sense of identity to the members of the organization. Third, culture makes a sort of commitment to something which is nothing more than self-interest. Fourth, culture makes social system stable (Oliver, 2006; quoted from Haghighat Monfaared \& Shaban Mayani, 2012, p. 67). Corporate culture is defined as "a pattern of shared values and 
beliefs that help individuals understand organizational performance, thus, creates norms of behavior in the organization". Schein (1985) emphasizes on "assumptions" that employees have in their organization.

While researchers disagree with type of aspect that shows organizational culture, we follow Denison and his colleagues who assumed four dimensions of organizational culture including adaptability, involvement in work, consistency and mission. Adaptability refers the extent where the organization can cope with change in its behavior, structure and systems with its external environment. Compatibility refers to the extent where an organization can maintain its shared values, beliefs and norms among the staff of organization. Involvement refers to the extent where an organization allows its members to intervene in the decision. And a mission refers to a clear and meaningful goals of the organization that are shared by all members of an organization. Empirically, organizational culture is related to the effectiveness of the organization and a strong and proper organizational culture encourages employees to get organizational successes. Moreover, organizational culture leads to sustainable competitive advantages that are not easily imitated. Research done on information systems has found a positive relationship between corporate culture and organizational performance. Organizational performance doesn't directly affect the organizational effectiveness, but it affects people's needs and guides them toward the goals of the organization. In the changing environment of the organization, both structured and unstructured information is obtained inside or outside the boundaries of the organization, such as exploration of data by staff. In an organization with a strong organizational culture, the ability of members for digesting information from an unknown world leads to effective and proper decision-makings. Organizational culture (adaptability, involvement in work, responsibility and consistency), forms the effectiveness of organization in terms of adaptability, engaging in work, responsibility and consistency in such a way that likely leads to increase in the effectiveness of the organization. Business intelligence systems continuously persist on searching new information using all channels of collecting data, using information system mechanism or mixing and covering data toward useful information, supervising on all the operational processing and following the main reason of problem.

Effectiveness of BI systems leads to effectiveness of organization which depends on the previous role of organizational culture. For this reason, common comprehension, values, norms and beliefs which accompanied by the members of organization provide a stable and desirable environment leading to free flow of information of providers and final customers among the hierarchy of the organization and various operational groups such as organizations that seek to make decisions quickly, minimize the problems, and aggravate the performance benefits (Shamsul Arefin et al., 2015).

\section{The Conceptual Model}

Figure 1 shows the conceptual model. This model is derived from the research of Shamsul Arefin et al. (2015). They conducted their research in organizational units of Bangladesh. The researcher plans to review the following model in Iran's airlines. In this model, organizational factors including organizational strategy, organizational structure, organizational process and organizational culture were studied on organizational effectiveness. BI systems were used as mediating variable and effectiveness in organization was assessed according to BI systems.

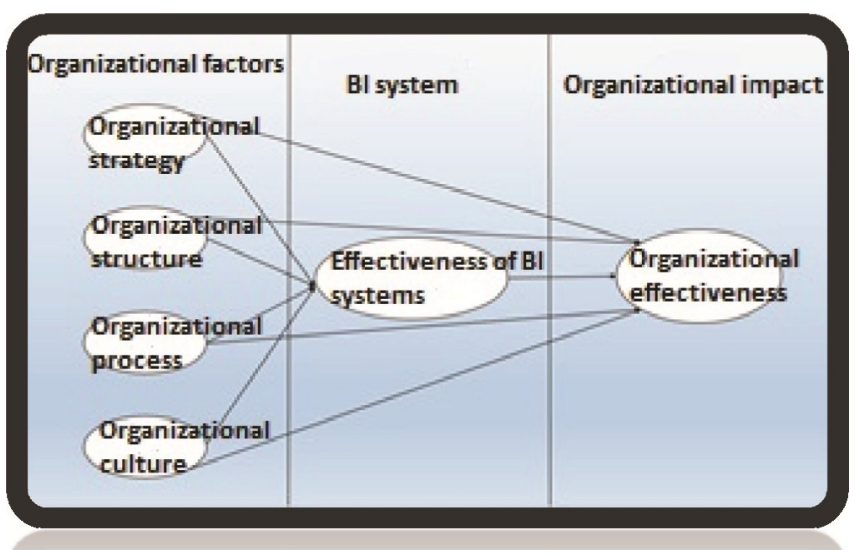

Figure 1. Conceptual model (Shamsul Arefin et al., 2015) 
According to the research model, organizational factors have an effect on organizational effectiveness in Iranian airlines due to the systems of Business Intelligence (BI). According to the conceptual model of research (Shamsul Arefin et al., 2015), hypotheses are as the following:

Hypothesis 1: organizational strategy has a significant positive impact on organizational effectiveness in Iran's airlines.

Hypothesis 2: organizational structure has a significant positive impact on organizational effectiveness in Iran's airlines.

Hypothesis 3: organizational processes have a significant positive impacton organizational effectiveness in Iran's airlines.

Hypothesis 4: organizational culture has a significant positive impact on organizational effectiveness in Iran's airlines.

Hypothesis 5: organizational strategy has a significant positive impact on the effectiveness of business intelligence systems in Iran's airlines.

Hypothesis 6: organizational structure has a significant positive impact on effectiveness of the system of business intelligence systems in Iran's airlines.

Hypothesis 7: organizational processes have a significant positive impact on effectiveness of business intelligence systems in Iran's airlines.

Hypothesis 8: organizational culture has a significant positive impact on the effectiveness of business intelligence systems in Iran's airlines.

Hypothesis 9: the effectiveness of business intelligence systems has a significant positive impact on organizational effectiveness.

\section{Research Methodology}

This study was conducted in Iran's aviation, therefore, it is in applied method and the type of data is descriptive -correlational and survey. All the airlines in Iran's airline ranging from full-governmental to full-private were selected as main society which were in total 17 out of them 13 airlines were cooperated.

The study population consisted of experts (experts, supervisors and managers of airlines). For sampling, non-random selection method based on possible non-random, judgment, and purposeful selection was used. To assess the organizational effectiveness, questionnaire of Lee and Choi (2003) was used. To assess the effectiveness of business intelligence systems, questionnaire of al-Bashir et al. (2008) was used. For organizational strategy, Venkatraman questionnaire (1989) was used. For organizational structure, questionnaire of Ferrell and Skinner (1988) was applied. For organizational processes, Tatikuda and Montopaus questionnaires were used (2001), and for organizational culture Denison and Misha questionnaire (1995) was used. To check the internal consistency or reliability of the questionnaire, Cronbach alpha coefficient was used and the validity was confirmed. To investigate the hypothesis, structural equation modeling was used.

Structural Equation Modeling (SEM) is a new statistical method and one of the most powerful methods of multivariate analysis. It is mainly used in multivariable subjects which can not be done in two-variable method where one independent variable and a dependent variable are considered each time.

Through structural equation, general or hypothetical structures with reasoning patterns can be confirmed with non-experimental data. In fact, structural equation modeling is a comprehensive statistical approach to test the assumptions on the relationship between observed variables and hidden ones.

\section{Data Analysis}

To run a factor analysis in order to ensure the adequacy of sampling and feasibility of factor, KMO test and Bartlett's test were applied using the software Spss 18. Results of the test showed that KMO statistics is 96.0 and since KMO is more than 6/0, adequate sampling is established. Chi square statistics in Bartlett sphericity test is 10785.52 which is significant at 95 percent $(\mathrm{P}$ value $000.0<$ ); therefore factorization can be justified. 
Table 1. Size (K.M.O) and result of Bartlett's sphericity test

\begin{tabular}{cc}
\hline Value & Index \\
\hline 96.0 & K.M.O \\
10785.52 & Bartlett's \\
666 & Degree of freedom \\
000.0 & Bartlett's Sig. level \\
\hline
\end{tabular}

In the path analysis model, conceptual model is tested. The result of the path analysis is shown in Figures 2 and 3. In the Table 2, measures of goodness of fit are given. Results indicate that the CFI index is 98.0 that is close to 1 and Index GFI is 99.0. AGFI index is 0.96 which is close to 1 . Therefore, measure of goodness of fit indicates that the model is reliable in total.

Table 2. Measures of goodness of fit of conceptual model

\begin{tabular}{ccccccc}
\hline RMSEA & AGFI & GFI & CFI & Df & $X^{2}$ & Index \\
\hline 074.0 & 96.0 & 99.0 & 98.0 & 614 & 1937.35 & Factorial analysis model \\
\hline
\end{tabular}

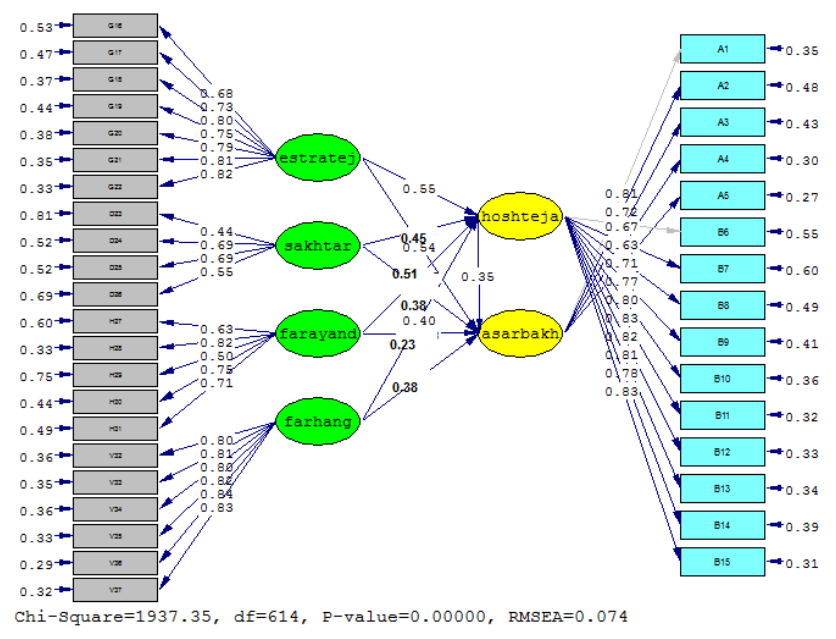

Figure 2. Model of measuring the research variables (standard coefficients)

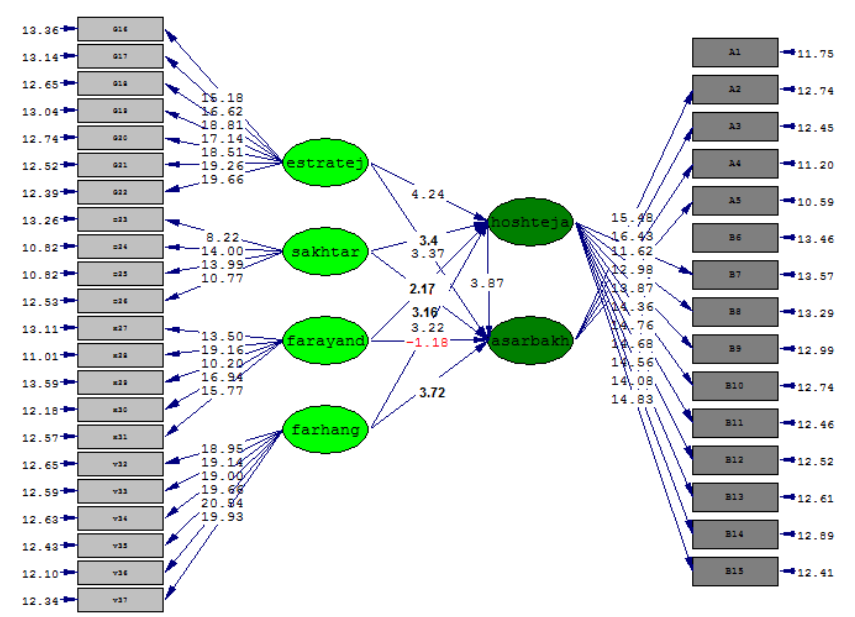

Figure 3. Model of measuring the research variables (T-statistic) 
Reviewing research hypotheses using path analysis model.

Table 3. Hypotheses test result

\begin{tabular}{ccccc}
\hline $\begin{array}{c}\text { Approval or rejection of } \\
\text { hypothesis }\end{array}$ & $\begin{array}{c}\text { Comparing with } \\
\text { critical value }\end{array}$ & $\begin{array}{c}\text { T } \\
\text { value }\end{array}$ & $\begin{array}{c}\text { Path standard } \\
\text { coefficient }\end{array}$ & Research hypothesis \\
\hline Significant & $37.3<96.1$ & 37.3 & 54.0 & $\begin{array}{c}\text { Impact of OI and organizational } \\
\text { effectiveness }\end{array}$ \\
Significant & $17.2<96.1$ & 17.2 & 38.0 & $\begin{array}{c}\text { Impact of organizational processes and } \\
\text { effectiveness }\end{array}$ \\
Non-significant & $18.1>-96.1$ & $18.1-$ & 23.0 & $\begin{array}{c}\text { Impact of organizational processes and } \\
\text { effectiveness }\end{array}$ \\
Significant & $72.3<96.1$ & $72 / 3$ & $38 / 0$ & $\begin{array}{c}\text { Impact of organizational culture and } \\
\text { effectiveness }\end{array}$ \\
Significant & $24.4<96.1$ & 24.4 & 55.0 & $\begin{array}{c}\text { Impact of organizational strategy and } \\
\text { effectiveness of BI systems }\end{array}$ \\
Significant & $4.3<96.1$ & 4.3 & 45.0 & $\begin{array}{c}\text { Impact of organizational structure and } \\
\text { effectiveness of BI systems }\end{array}$ \\
Significant & $17.2<96.1$ & 17.2 & 51.0 & $\begin{array}{c}\text { Impact of organizational processes and } \\
\text { effectiveness of BI systems }\end{array}$ \\
Significant & $22.3<96.1$ & 22.3 & 23.0 & 35.0 \\
Significant & $87.3<96.1$ & 87.3 & $\begin{array}{c}\text { Impact of organizational culture and } \\
\text { effectiveness of BI systems }\end{array}$
\end{tabular}

\section{Conclusion}

In this research, organizational strategy has a positive and significant impact on organizational effectiveness in Iran's airlines. This means that the more accurate planning we have for optimum usage of organizational facilities, the more organizational effectiveness we will have which is consistent with results of researches of Vaezi and Frouzanfar (2013) and Shamsul Arefin et al. (2015). According to the results of the research, organizational structure has a significant positive impact on organizational structure in Iran's airlines. It can be said that if communications are properly defined in an organization, organizational effectiveness is in similar increased that agrees with the research of Diez et al. (2010), Aghaei et al. (2011) and Shamsul Arefin et al. (2015). Organizational processes have no significant effect on organizational effectiveness in Iran's airlines and this results do not agree with the those of Al-Bashir et al. (2008), Banrechy and Mishra (2015) and Shamsul Arefin et al. (2015). According to the research, organizational culture has a significant positive impact on organizational effectiveness in Iran's airlines. This means that with an increase in organizational culture, organizational effectiveness is also increased. This result is consistent with the results of the investigation of Seyed Naqavi et al. (2010), Nazari et al. (2015), Aghaei et al. (2011) and Shamsul Arefin et al. (2015). Organizational strategy has an impact on the effectiveness of business intelligence systems in Iran's airlines. In this research, organizational structure has an impact on effectiveness of BI systems in Iran's airlines. The more accurate organizational structure, more is the effectiveness of business intelligence which agrees with researches of Vaezi and Forouzanfar (2013) and Shamsol Arefin (2015). Organizational processes have a positive and significant impact on effectiveness of BI systems in Iran's airlines. This means that if the processes are properly followed, effectiveness of the business intelligence system also increases which agrees with researches of Shamsol Arefin et al. (2015).

According to the research results, organizational culture has a positive and significant impact on effectiveness of business intelligence systems in Iran's airlines. It can be concluded that with strengthening of the organizational culture, effectiveness of business intelligence systems also increases. This result is consistent with the results obtained from Haghighat Monfared and Shaban Mayani (2012), Vaezi and Forouzanfar (2013) and Shamsol Arefin et al. (2015). The effectiveness of business intelligence systems has a positive and significant impact onorganizational effectiveness. This means that if effectiveness of business intelligence systems is strengthened, organizational effectiveness also increases. This result is consistent with the results of the research by Turban et 
al. (2007), Ardalan et al. (2012) and Shamsul Arefin et al. (2015). According to research results, staff of companies are aware of significance and role of arranging the strategy more than ever. And courses of arranging the strategy are held in working environment so that organizational effectiveness can be increased by strengthening the organizational strategy. We need to explain organizational structure in Iran accurately, since informative structures can help strengthen organizational effectiveness. Since organizational culture has a positive impact on organizational effectiveness in Iran's airlines with correlation coefficient of $(0.38)$, it is suggested that organizations implement their human resources activities in such a way that an atmosphere of trust, cooperation, social capital partnership and hope can be strengthened in organization and preventing the disappointment in the current environment of organization, leading to high effectiveness. It seems that policy makers and planners must improve the quality of work according to available tools and facilities. They can also establish a sort of balance and active integration in the organization and also can strengthen the social correlations with the aim of establishing common objectives. The researchers who are interested are suggested to conduct the research by tracking course through questionnaire among all the staff of organizations and through various rankings. Then, level of stability and established effects can be specified through long-term research plans. Also it is suggested to cope with identification fields of other cognitive, motivation and behavioral variables which are related to organizational effectiveness in the future researches. Experimental interferences can also be conducted in order to identify impacts of BI effectiveness on motivation, effort, performance and other positive returns. In order to obtain more accurate results, researchers are advised to compare airlines based on research variables.

\section{References}

Abzari, M., \& Deloni, M. (2006). Culture Management Organization (concepts, patterns, change) excellence-oriented approach (1st ed.). Ghasede-sahar publication.

Aghaei, M., Aghaei, A., \& Aghaei, R. (2011). Evaluation of influence between strategy, culture, structure, organizational effectiveness and knowledge management. Article onimprovement and transformation Management, XXI(65), 105-125.

Ardalan, M., Alexander, A., \& Gilani, M. (2012). Knowledge management, business intelligence and organizational effectiveness. Strategic management studies, 12, 71-100.

Banerjee, M., \& Mishra, M. (2015, October 21). Retail supply chain management practices in India: A business intelligence perspective. Journal of Retailing and Consumer Services Available online.

Denison, D. R., \& Mishra, A. K. (1995). Toward a theory of organizational culture and Effectiveness. Organization Science, 6(2), 204-223. https://doi.org/10.1287/orsc.6.2.204

Elbashir, M. Z., Collier, P. A., \& Davern, M. J. (2008). Measuring the effects of business intelligence systems: The relationship between business process and organizational performance. International Journal of Accounting Information Systems, 9(3), 135-153. https://doi.org/10.1016/j.accinf.2008.03.001

Ferrell, O. C., \& Skinner, S. J. (1988). Ethical behavior and bureaucratic structure in marketing research organizations. Journal of Marketing Research, 25(1), 103-109. https://doi.org/10.2307/3172930

Fink, L., Yogev, N., \& Even, A. (2016, May 27). Business intelligence and organizational learning: An empirical investigation of value creation processes. Information \& Management.

Haghighat Monfared, J., \& Shabani Mayani, M. (2012). Reviewing the effect of content dimensions of organization according to BI effectiveness according to role of management-Case Study: Saman Bank. (Researcher) Management Journal, IX(27), 65-84.

Javaherikamel. (2014). Organizational effectiveness. Baqeraloloum Institute.

Lajevardi, S. J., \& Rahimi Pour, A. (2012). Business intelligence and its impact on improving performance management ports. Didgah Journal, 3-30.

Nazari, R., Ghassemi, H., \& Sohrabi, Z. (2015). The relationship between communication skills, leadership styles in organizational culture and manager's efficiency in sport organizations: Structural equation modeling. A study sports management and motor behavior, 21, 93-102.

Rahim, G. H., Nowruzi, M., \& Sari Olghalam, N. (2012). Reviewing the relationship between multiple intelligences managers with organizational effectiveness in Gas Company of Azarbaijanesharghi. (Researcher) Management Journal, IX(25), 21-34. 
Robins, A. (1995). Organization theory (structure, design, and application) (3rd ed.). Tehran: Publication of Saffar-Eshraghi.

Shamsul Arefin, Md., Rakibul, H., \& Yukun, B. (2015). The impact of business intelligence on organization's effectiveness: An empirical study. Journal of Systems and Information Technology, 17(3), 263-285. https://doi.org/10.1108/JSIT-09-2014-0067

Tatikonda, M. V., \& Montoya-Weiss, M. M. (2001). Integrating operations and marketing perspectives of product innovation: The influence of organizational process factors and capabilities on development performance. Management Science, 47(1), 151-172. https://doi.org/10.1287/mnsc.47.1.151.10669

Vaezi, R., \& Forouzanfar, H. (2013). Structural Model of organizational effectiveness: Assessing the direct and indirect effects of organizational factors and knowledge management in the company of Saipa. Journal of Development and Evolution Management, 14, 9-17.

Weinberga, B. D., Ruyterb, K., Dellarocasc, C., Buckd, M. K., \& Debbie, I. (2013). Destination Social Business: Exploring an Organization's Journey with Social Media. Collaborative Community and Expressive $\begin{array}{llll}\text { Individuality. Journal of Interactive } & \text { Marketing, 27(4), }\end{array}$ https://doi.org/10.1016/j.intmar.2013.09.006

\section{Copyrights}

Copyright for this article is retained by the author(s), with first publication rights granted to the journal.

This is an open-access article distributed under the terms and conditions of the Creative Commons Attribution license (http://creativecommons.org/licenses/by/4.0/). 